\title{
Patterns of injury and outcomes in the elderly patient with rib fractures: a multicenter observational study
}

\author{
Mark G. Van Vledder ${ }^{1}\left(\mathbb{D} \cdot\right.$ Vicky Kwakernaak $^{1} \cdot$ Tjebbe Hagenaars $^{1} \cdot$ Esther M. M. Van Lieshout $^{1}$. \\ Michiel H. J. Verhofstad ${ }^{1}$. On behalf of the South West Netherlands Trauma Region Study Group
}

Received: 29 January 2018 / Accepted: 5 June 2018 / Published online: 15 June 2018

(c) The Author(s) 2018

\begin{abstract}
Background High rates of pneumonia and death have been reported among elderly patients with rib fractures. This study aims to identify patterns of injury and risk factors for pneumonia and death in elderly patients with rib fractures.

Methods A retrospective multicenter observational study was performed using data registered in the national trauma registry between 2008 and 2015 in the South West Netherlands Trauma region. Data regarding demographics, mechanism of injury, pulmonary and cardiovascular history, pattern of extra-thoracic and intrathoracic injuries, ICU admission, length of stay, and morbidity and mortality following admission were collected.

Results Eight hundred eighty-four patients were included. Median age was 76 years $\left(\mathrm{P}_{25}-\mathrm{P}_{75} 70-83\right) .235$ patients (26.6\%) were 81 years or older. Moderate or worse extra-thoracic injuries were present in 456 patients (51.6\%), of whom 146 (16.6\%) had severe head injuries and $45(5.1 \%)$ severe spinal injuries. Median ISS was $9\left(\mathrm{P}_{25}-\mathrm{P}_{75} 5-18\right)$. The rate of pneumonia was $10 \%(n=84)$. Ten percent of patients $(n=88)$ died. Risk factors for in-hospital mortality included age (OR 3.4; $p=0.003)$, presence of COPD (OR 1.3; $p=0.01$ ), presence of cardiac disease (OR 2.6; $p=0.003$ ), severe or worse head (OR 3.5; $p<0.001$ ), abdominal (OR 6.8; $p=0.004$ ) and spinal injury (OR 4.6; $p=0.011$ ) by AIS, number of rib fractures (OR 2.6; $p=0.03$ ), and need for chest tube drainage (OR $2.1 ; p=0.021$ ).

Conclusions Pneumonia and death occur in about $10 \%$ of elderly patients with rib fractures. Apart from the severity of thoracic injuries, the presence and severity of extra-thoracic injuries and cardiopulmonary comorbidities are associated with poor outcome.
\end{abstract}

Keywords Rib fractures · Geriatric trauma $\cdot$ Registry study

\section{Introduction}

Rib fractures do commonly occur in elderly patients (65 years and older) following blunt thoracic trauma [1]. Although these injuries are often caused by low-energy trauma (e.g., fall from standing height), adverse outcome such as pneumonia, respiratory failure and death are frequently observed [2,3]. Immediate recognition of patients at

On behalf of the South West Netherlands Trauma Region Study Group members are listed in acknowledgements.

Mark G. Van Vledder

m.vanvledder@erasmusmc.nl

1 Trauma Research Unit, Department of Surgery, Erasmus MC, University Medical Center Rotterdam, P.O. Box 2040, 3000 CA Rotterdam, The Netherlands risk for developing such adverse events after being admitted for thoracic injuries resulting from blunt thoracic trauma is, therefore, of vital importance.

Apart from risk stratification, treatment decisions regarding rib fractures may be impacted by the presence of certain patient characteristics or extra-thoracic injuries. For instance, oral anticoagulant use, the presence of severe spinal injuries or severe brain injury may preclude epidural analgesia or surgical rib fixation. Data with regard to patterns of injury among elderly patients with rib fractures are especially helpful when considering such treatment regimens.

The aim of the current study was to identify risk factors for pneumonia and death in conservatively treated elderly patients with rib fractures. Furthermore, patterns of injury were investigated. 


\section{Patients and methods}

For this retrospective observational multicenter study, patients were identified using data from the Dutch national trauma registry. This registry includes all patients admitted to any hospital in the Netherlands following any traumatic injury. Medical case records are reviewed directly after discharge and data are inserted in the national database by trained data managers. Study design, data analysis and drafting of the manuscript were performed according to the STROBE guidelines for cohort studies. The study protocol was approved by the institutional review board of the coordinating hospital.

For this study, the national trauma registry was queried for elderly patients (65 years or older) with rib fractures. Patients were included if they were admitted between January 1st, 2008 and December 31st, 2015 in one of ten different hospitals in the South West Netherlands Trauma region and had at least one rib fracture following blunt trauma. Patients were excluded from the analysis if they died within $24 \mathrm{~h}$ of admission due to extra-thoracic injuries, had cervical spine injury with complete paralysis of respiratory muscles, if they underwent surgical rib fixation or if they had no data in their case record. If patients were transferred to another hospital directly from the emergency room, their cases were only included in the analysis if the hospital eventually admitting the patient was one of the cooperating hospitals.

In the Dutch trauma system, each hospital is assigned a specific level of trauma-expertise. Level-1 hospitals are dedicated trauma centers equipped to take care of patients with multiple, potentially life-threatening injuries. Level-2 hospitals are equipped to receive and treat hemodynamic stable patients with multiple (non-acutely life-threatening) injuries. Level-3 hospitals generally only admit patients with single injuries that do not pose an acute threat to the patient's life. Triage with regard to which type of hospital a patient should be transported is performed by ground emergency medical personnel, if necessary assisted by a Dutch physician staffed helicopter emergency medical services (HEMS).

The following variables were collected from the national trauma registry: age, gender, trauma mechanism, hospital length of stay, ICU admission, length of ICU admission, injury severity score (ISS), and specific injuries as coded by the abbreviated injury scale (AIS). Three AIS groups were created for each body region for easy comparison: 1 none or only minor injuries (AIS 0 or 1), 2 moderate injuries (AIS 2), 3 severe or worse injuries (AIS 3 or higher). Registry data were supplemented with data from a retrospective chart review in which the following variables were collected: presence of cardiovascular disease, presence of pulmonary disease, medication, hemo- or pneumothorax requiring chest-tube drainage, diagnosis of pneumonia (progressive or new infiltrate on chest X-ray combined with two of the following characteristics; temperature alteration $<36.0^{\circ} \mathrm{C}$ or $>38.3{ }^{\circ} \mathrm{C}$, purulent sputum or leukocytosis $<5000$ cells $/ \mathrm{mm}^{3}$ or $>10,000$ cells $\left./ \mathrm{mm}^{3}\right)$, and late respiratory failure $(>24 \mathrm{~h}$ after admission) requiring tracheal intubation and mechanical ventilation

Data were analyzed using the statistical package for the social sciences (SPSS) version 23.0 (SPSS, Chicago, Ill, USA). Missing values were not imputed. For continuous non-parametric data, the median and percentiles are reported. Distribution of continuous data was checked using the Shapiro-Wilk test for normality. For categorical data, numbers and frequencies are reported. Exploratory analysis to detect any associations between the primary and secondary outcome variables and patient, injury and treatment characteristics was performed using the nonparametric Mann-Whitney test for continuous variables and Pearson chi-square test for categorical variables. Risk factors for death and pneumonia were further investigated using univariable logistic regression analysis. Odds ratios, 95\% confidence intervals and $p$ values are reported. Independent variables with a statistically significant association with the outcome variable in the univariable analysis were included in a multivariable binary logistic regression model in a stepwise (backward and forward) fashion. Goodness of fit was determined using Nagelkerke $R^{2}$ and the Hosmer and Lemeshow test. A $p$ value of $<0.05$ was considered to be statistically significant.

\section{Results}

\section{Patient characteristics}

A total of 1238 patients were identified in the database meeting the search criteria. After excluding 354 patients that fulfilled one or more of the exclusion criteria, 884 patients remained for further analysis (Fig. 1). Patient demographics are provided in Table 1. About two-third of patients were between 65 and 80 years old. Cardiac comorbidity was present in one-fifth of patients. Pulmonary disease was present in $10.5 \%$ of patients. The mechanism of injury was a fall from standing height in $43.7 \%$ of patients.

An overview of patterns of injury is provided in Table 2. To account for pre-hospital triage of patients and subsequent referral to level-1, level-2 or level-3 centers, data are stratified by the level of the receiving hospital. While about a quarter of patients had four or more rib fractures, a clinically manifest flail chest was present in only $2.5 \%$ of patients. Chest tube drainage was performed in $17 \%$ of patients. Injury severity scores and the number and severity of injuries were significantly higher in the level-1 trauma center than in the level- 2 and level-3 centers. Over half of all 
Fig. 1 Flowchart of patients included and excluded in the

1238 patients analysis

Exclusion $(\mathbf{n = 3 5 4 )}$
$\begin{array}{ll}\mathbf{2 1 0} & \text { no rib fractures } \\ \mathbf{3 5} & \text { Treated in other hospital } \\ \mathbf{1 3} & \text { Underwent rib fixation } \\ \mathbf{7} & \text { Complete spinal cord laceration above C3 } \\ \mathbf{6} & \text { Penetrating injury } \\ \mathbf{3 0} & \text { Dead due to extra-thoracic injuries }<24 \text { hours } \\ \mathbf{1 2} & \text { No data in case record } \\ \mathbf{1} & \text { Double registration }\end{array}$

884 patients patients had moderate (23.3\%), or severe or worse (28.3\%) extra-thoracic injuries. In the participating level-1 hospital this was as high as $65.1 \%$ of patients. Of the 238 patients with four or more rib fractures, ninety (37.8\%) patients also had severe or worse extra-thoracic injuries. More specifically, 53 patients $(22.3 \%)$ also sustained severe or worse head injury and 19 patients (8.0\%) also sustained severe or worse spinal injuries.

\section{Outcomes}

Eighty-eight patients (10.0\%) died during hospital admission. Eighty-four patients (9.5\%) developed pneumonia. Ninety-eight patients required tracheal intubation and mechanical ventilation (11.1\%), of whom 28 (3.2\%) of patients were intubated due to delayed respiratory insufficiency. Two hundred thirteen patients $(24.1 \%)$ were transferred to the ICU straight from the Emergency Department and 43 patients $(4.9 \%)$ were admitted to the ICU at a later moment from the clinical ward due to delayed respiratory problems. Of all patients transferred to the ICU, only 59 patients (24.8\%) had none or minor extra-thoracic injuries. More specifically, of the patients admitted to the ICU, 93 (39.1\%) had severe or worse head injuries. In addition, in those requiring intubation and mechanical ventilation, severe or worse head injury was present in 63 cases (64.3\%).

Median hospital length of stay was 8 days $\left(\mathrm{P}_{25}-\mathrm{P}_{75}\right.$ 4-14 days). For those patients admitted to the ICU, median length of stay in ICU was 4 days $\left(\mathrm{P}_{25}-\mathrm{P}_{75} 2-10\right.$ days). Five hundred eighteen patients (57.7\%) were discharged directly to their prior housing facility after discharge.

\section{Factors associated with in-hospital death}

Patient and injury characteristics associated with in-hospital mortality are listed in Table 3. Mortality was higher in the level-1 trauma center than in level 2 and 3 hospitals. Moreover, increasing age and pre-existing conditions such as cardiac disease and COPD were associated with an increased probability of in-hospital mortality. Injury-specific characteristics such as the number of rib fractures, the need for chest-tube drainage and the severity of thoracic and extra-thoracic injuries are also predicted in hospital death. In patients with four or more rib fractures without or with only minor or moderate extra-thoracic injuries, inhospital mortality was $7.4 \%$. In comparison, mortality in patients with four or more rib fractures and severe or worse extra-thoracic injuries was $23.3 \%(p=0.002)$. In patients with a limited number of rib fractures $(<4)$ and none or minor extra-thoracic injuries, in-hospital mortality was $3 \%$. In a multivariable analysis, the model with the best fit was obtained after including the following variables in the model: age, presence of COPD GOLD 2 or worse, presence of cardiac disease, presence and severity of head, abdominal, and spinal injury by AIS, number of rib fractures and need for chest tube drainage (Table 4). The explained variance of the model was $21 \%$. 
Table 1 Baseline characteristics of 884 elderly patients with rib fractures

\begin{tabular}{|c|c|c|}
\hline Characteristic & $\operatorname{Median}\left(\mathrm{P}_{25}-\mathrm{P}_{75}\right)$ & Number $(\%)$ \\
\hline \multicolumn{3}{|l|}{ Age } \\
\hline Age & $76(70-83)$ & \\
\hline Age $65-80$ & & $580(65.6 \%)$ \\
\hline Age $81-90$ & & $235(26.6 \%)$ \\
\hline Age $>90$ & & $69(7.8 \%)$ \\
\hline \multicolumn{3}{|l|}{ Gender } \\
\hline Female & & $369(41.7 \%)$ \\
\hline Male & & $515(58.3 \%)$ \\
\hline \multicolumn{3}{|l|}{ History of cardiac disease } \\
\hline None & & $711(80.4 \%)$ \\
\hline Myocardial infarction & & $85(9.6 \%)$ \\
\hline $\begin{array}{l}\text { Congestive heart failure (any } \\
\text { NYHA grade) }\end{array}$ & & $59(6.7 \%)$ \\
\hline Unknown & & $29(3.3 \%)$ \\
\hline \multicolumn{3}{|l|}{ Oral anticoagulation use } \\
\hline Yes & & $151(17.1 \%)$ \\
\hline No & & $618(81.2 \%)$ \\
\hline Unknown & & $15(1.7)$ \\
\hline \multicolumn{3}{|l|}{ History of COPD } \\
\hline None & & $764(86.4 \%)$ \\
\hline COPD (any GOLD stadium) & & $93(10.5 \%)$ \\
\hline Unknown & & $27(3.1 \%)$ \\
\hline \multicolumn{3}{|l|}{ Mechanism of Injury } \\
\hline Low energetic fall & & $387(43.7 \%)$ \\
\hline High energetic fall & & $147(16.6 \%)$ \\
\hline Bike or pedestrian & & $150(17.0 \%)$ \\
\hline Motor vehicle accident & & $99(11.2 \%)$ \\
\hline Other & & $17(1.9 \%)$ \\
\hline Unknown & & $82(9.3 \%)$ \\
\hline
\end{tabular}

\section{Factors associated with pneumonia}

Patient and injury characteristics associated with pneumonia are listed in Table 3. While increasing age did not increase the probability of pneumonia, male patients had a higher risk of pneumonia when compared to female patients. Preexisting chronic obstructive pulmonary disease was associated with a $23.7 \%$ chance of developing pneumonia. Injuryspecific characteristics such as the number of rib fractures, need for chest tube drainage, and the severity of intra-thoracic and extra-thoracic injuries were also associated with an increased probability of developing pneumonia. In patients with four or more rib fractures without or with minor or moderate extra-thoracic injuries, $6.9 \%$ of patients developed pneumonia. In comparison, of 89 patients with four or more rib fractures and severe or worse extra-thoracic injuries 23 patients $(25.8 \%)$ developed pneumonia $(p<0.001)$. In patients with none or minor extra-thoracic injuries and 1-3 rib fractures, the rate of pneumonia was $5.6 \%$. In the multivariable analysis, the model with the best fit was obtained after including the following variables in the model: female gender, presence of COPD, number of rib fractures, need for chest tube drainage, and presence and severity of head and abdominal injury by AIS (Table 5). The explained variance of the model was $17 \%$.

\section{Discussion}

This multicenter observational study aimed to identify risk factors for pneumonia and death in a large cohort of elderly patients with traumatic rib fractures. In addition, patterns of injury that may influence outcome and further treatment were investigated. Almost half of patients sustained their injuries after a fall from standing height. About a quarter of patients had four or more rib fractures. Moderate or worse extra-thoracic injuries were present in more than half of patients. Increasing age, comorbidity, the number of rib fractures and the severity of extra-thoracic injuries were all associated with an increased risk of pneumonia and in-hospital death, which occurred in about $10 \%$ of patients.

Mortality rates up to $22 \%$ have been reported in elderly patients with multiple rib fractures [2]. As our data show, mortality rates differ dramatically depending on the type of population that is studied. In the current study, patients admitted to level-3 trauma centers had a mortality rate of $5.4 \%$ while patients admitted to level- 1 hospitals had a mortality rate of almost $22 \%$. The risk factors for pneumonia and death that were identified in this study have been identified by others as well [4]. Increasing age and the presence of cardiopulmonary comorbidities are well-known risk factor for in-hospital mortality in any trauma patient [5]. A recent study by Harrington et al. including patients from both level-1 centers as well as lower level trauma centers found a mortality rate of $4.9 \%$. Apart from injury severity, age and the presence of congestive heart failure were independently associated with in-hospital mortality [6].

Another frequently reported risk factor for pneumonia and death is the number of rib fractures. In our study-like many others-the presence of four or more rib fractures was independently associated with an increased risk of pneumonia and death. A recent study by Shulzhenko et al. reported a much higher threshold (eight or more fractured ribs) for an elevated risk of death [7]. One of the most likely reasons for this is the increased use of CT scanning in trauma patients, resulting in a higher rate of detected rib fractures when compared to conventional chest radiographs creating a potential detection bias.

When considering these risk factors, the validity of our statistical models should be taken into consideration. The statistical models we created to predict pneumonia 
Table 2 Patterns of intrathoracic and extra-thoracic injury stratified by level of admitting hospital

\begin{tabular}{|c|c|c|c|c|c|}
\hline Characteristics & $\begin{array}{l}\text { All } \\
N=884\end{array}$ & $\begin{array}{l}\text { Level } 1 \\
N=235\end{array}$ & $\begin{array}{l}\text { Level } 2 \\
N=425\end{array}$ & $\begin{array}{l}\text { Level } 3 \\
N=224\end{array}$ & $p$ value \\
\hline \multicolumn{6}{|l|}{ ISS } \\
\hline Median $\left(\mathrm{P}_{25}-\mathrm{P}_{75}\right)$ & $9(5-18)$ & $22(16-33)$ & $9(5-13)$ & $9(4-10)$ & $<0.001$ \\
\hline$<16$ & $605(68.4)$ & $55(23.4)$ & $349(82.1)$ & $201(89.7)$ & $<0.001$ \\
\hline$\geq 16$ & $279(31.6)$ & $180(76.6)$ & $76(17.9)$ & $23(10.3)$ & \\
\hline \multicolumn{6}{|l|}{ Head injury } \\
\hline None or minor & $674(76.2)$ & $109(46.4)$ & $361(84.9)$ & $204(91.1)$ & $<0.001$ \\
\hline Moderate & $64(7.2)$ & $15(6.4)$ & $35(8.2)$ & $14(6.3)$ & \\
\hline Severe or worse & $146(16.6)$ & $111(47.2)$ & $29(6.8)$ & $6(2.3)$ & \\
\hline \multicolumn{6}{|l|}{ Abdominal injury } \\
\hline None or minor & $843(95.3)$ & $211(89.8)$ & $413(97.2)$ & $218(97.3)$ & 0.001 \\
\hline Moderate & $29(3.3)$ & $16(6.8)$ & $9(2.1)$ & $4(1.8)$ & \\
\hline Severe or worse & $13(1.4)$ & $8(3.4)$ & $3(0.7)$ & $2(0.9)$ & \\
\hline \multicolumn{6}{|l|}{ Spinal injury } \\
\hline None or minor & 774 (87.6) & $157(66.8)$ & $404(95.1)$ & $213(95.1)$ & $<0.001$ \\
\hline Moderate & $65(7.4)$ & $44(18.7)$ & $14(3.3)$ & $7(3.1)$ & \\
\hline Severe or worse & $45(5.1)$ & $34(14.5)$ & 7 (1.6) & $4(1.8)$ & \\
\hline \multicolumn{6}{|l|}{ Lower extremity injury } \\
\hline None or minor & $765(86.5)$ & 181(77.0) & $377(88.7)$ & $207(92.4)$ & $<0.001$ \\
\hline Moderate & $49(5.5)$ & $21(8.9)$ & $15(3.5)$ & $13(5.8)$ & \\
\hline Severe or worse & $70(7.2)$ & $33(14.0)$ & $33(7.8)$ & $4(1.8)$ & \\
\hline \multicolumn{6}{|l|}{ Thoracic injury } \\
\hline Minor & $135(15.3)$ & $25(10.6)$ & $68(16.0)$ & $42(18.8)$ & $<0.001$ \\
\hline Moderate & $308(34.8)$ & $53(22.6)$ & $165(38.8)$ & $90(40.2)$ & \\
\hline Severe or worse & $441(49.9)$ & $157(66.8)$ & $192(45.2)$ & $92(41.1)$ & \\
\hline \multicolumn{6}{|l|}{ Extra-thoracic injuries (any) } \\
\hline None or minor & $428(48.4)$ & $39(16.6)$ & $248(58.4)$ & $141(62.9)$ & $<0.001$ \\
\hline Moderate & $206(23.3)$ & $43(18.3)$ & $98(23.1)$ & $65(29.0)$ & \\
\hline Severe or worse & $250(28.3)$ & $153(65.1)$ & $79(18.6)$ & $18(8.0)$ & \\
\hline \multicolumn{6}{|l|}{ Number of rib fractures } \\
\hline Single & $168(19.0)$ & $32(13.6)$ & $83(19.5)$ & $53(23.7)$ & $<0.001$ \\
\hline $2-3$ & $341(38.6)$ & $68(28.9)$ & $171(40.2)$ & $102(45.5)$ & \\
\hline$\geq 4$ & $232(26.2)$ & $92(39.1)$ & $100(23.5)$ & $40(17.9)$ & \\
\hline Multiple not further specified & $143(16.2)$ & $43(18.3)$ & $71(16.7)$ & $29(12.9)$ & \\
\hline \multicolumn{6}{|c|}{ Hemo-or pneumothorax requiring drainage } \\
\hline Yes & $144(17.2)$ & $72(31.2)$ & $43(10.1)$ & $29(12.9)$ & $<0.001$ \\
\hline No & $735(82.7)$ & $159(68.8)$ & $381(89.9)$ & $195(87.1)$ & \\
\hline Unknown & $5(0.1)$ & & & & \\
\hline \multicolumn{6}{|l|}{ Flail chest } \\
\hline No & $22(2.5)$ & $223(95.3)$ & $412(98.1)$ & $211(98.6)$ & 0.044 \\
\hline Yes & $846(95.7)$ & $11(4.7)$ & $8(1.9)$ & $3(1.4)$ & \\
\hline Unknown & $16(1.8)$ & & & & \\
\hline
\end{tabular}

and death had a poor predictive value with regard to the explained variance in pneumonia and death (17 and $21 \%$, respectively). This suggests that other important predictors of mortality and pneumonia were not captured in the current study. So-called frailty indices - a composite measure for physical activities, nutritional status, social activities, cognitive performance and overall health status — are validated tools for assessing functional status in the elderly and have been shown to predict outcomes in a variety of surgical diseases, including trauma [8, 9]. A recent study by Joseph et al. showed that frailty was a better predictor of outcomes in the aging trauma patient when compared to age alone. Patients with frailty were more likely to have in-hospital complications and had an increased chance of dying or being 
Table 3 Univariable analysis of factors associated with in-hospital death and pneumonia

$\begin{array}{llllll}\text { Number of patients } & \text { Odds ratio }(95 \% \text { CI) } & p \text { value } & \text { Number of patients with } & \text { Odds ratio }(95 \% \text { CI) } & p \text { value }\end{array}$
dead $(n=88)$ pneumonia $(n=84)$

Age

\section{5-80}

$81-90$

$\geq 91$

Gender

Male

Female

History of cardiac disease

$\begin{array}{ll}\text { No } & 53(7.5 \%) \\ \text { Yes } & 22(15.3 \%) \\ \text { Unknown } & 13\end{array}$

History of COPD GOLD 2 or worse/any grade ${ }^{\mathrm{a}}$

$\begin{array}{lll}\text { No } & 69(8.3 \%) & \\ \text { Yes } & 6(25 \%) & 3.7(1.4-9.6) \\ \text { Unknown } & 13 & \end{array}$

Unknown

Number of rib fractures

Single
$2-3$
$\geq 4$
Multiple NFS
Need for CTD
No
Yes
Thoracic injuries
Minor

Moderate

$$
12(7.1 \%)
$$

$19(5.6 \%)$

$31(13.4 \%)$

$0.8(0.4-1.6)$

$26(18.2 \%)$

$2.0(1.0-4.0)$

$2.9(1.4-6.0)$

$56(7.6 \%)$

$29(20.1 \%)$

$3.1(1.9-5.0)$

$9(6.7 \%)$

Severe or worse

$16(5.2 \%)$

$0.7(0.3-1.8)$

$2.3(1.1-4.8)$

Extra-thoracic injuries

None or minor

$63(14.3 \%)$

Moderate

$25(5.8 \%)$

Severe or worse

$16(7.8 \%)$

$47(18.8 \%)$

$1.4(0.7-2.6)$

$3.7(2.2-6.3)$

Head injury

None or minor

$$
64(8.3 \%)
$$

Moderate

$$
11(16.9 \%)
$$

Severe or worse

$13(28.9 \%)$

$0.4(0.1-1.6)$

$3.4(2.1-5.5)$

Spinal injury

None or minor

$$
53(7.9 \%)
$$

Moderate

$2(3.1 \%)$

Severe or worse

$33(22.6 \%)$

$2.6(1.0-6.6)$

$6.2(2.0-19.5)$

Abdominal injury

None or minor

Moderate

$77(9.1 \%)$

Severe or worse

$6(20.7 \%)$

$5(38.5 \%)$

Level of admitting hospital

\begin{tabular}{lll} 
Level 1 & $51(21.7 \%)$ & \\
Level 2 & $25(5.9 \%)$ & $0.2(0.1-0.4)$ \\
Level 3 & $12(5.4 \%)$ & $0.2(0.1-0.4)$ \\
\hline
\end{tabular}

$\begin{array}{ll} & 59(10.4 \%) \\ 0.37 & 20(8.6 \%) \\ 0.008 & 5(7.5 \%)\end{array}$

$64(12.7 \%)$

$0.46 \quad 20(5.5 \%)$

$67(9.6 \%)$

$0.003 \quad 16(11.2 \%)$

1

$61(8.1 \%)$

$0.007 \quad 22(23.7 \%)$

1

$7(4.3 \%)$

$0.49 \quad 27(8.0 \%)$

$0.051 \quad 33(14.0 \%)$

$0.004 \quad 17(12.8 \%)$

$1.9(0.8-4.6)$

$3.4(1.5-7.9)$

$3.8(1.5-9.2)$

$57(7.9 \%)$

$<0.001 \quad 27(19.0 \%)$

$2.5(1.7-4.5)$

$<0.001$

$6(4.6 \%)$

$0.77 \quad 23(7.5 \%)$

$0.02 \quad 55(12.7 \%)$

$1.7(0.7-4.3)$

$3.0(1.3-7.2)$

0.26

0.01

$31(7.3 \%)$

$0.36 \quad 11(5.5 \%)$

$<0.001 \quad 42(17.1 \%)$

$0.7(0.4-1.5)$

$2.6(1.6-4.3)$

$<0.001$

$53(8.0 \%)$

$0.18 \quad 6(9.7 \%)$

$<0.001 \quad 25(17.5 \%)$

$1.2(0.5-3.0)$

$2.4(1.5-4.1)$

0.64

0.001

$64(8.4 \%)$

$0.04 \quad 12(18.8 \%)$

$8(18.2 \%)$

$2.5(1.3-4.9)$

0.008

$2.4(1.1-2.4)$

0.32

$73(8.8 \%)$

$0.44 \quad 7(24.1 \%)$

$0.002 \quad 4(30.8 \%)$

$3.3(1.4-8.0)$

0.008

$4.6(1.4-15.3)$

0.013

$38(16.3 \%)$

$<0.001 \quad 31(7.5 \%)$

$<0.001 \quad 15(6.8 \%)$

$0.4(0.3-0.7)$

0.001

$0.4(0.2-0.7)$

0.002

$C T D$ chest tube drainage, $C I$ confidence interval

${ }^{\mathrm{a}}$ COPD GOLD 2 or worse for in-hospital death, any grade COPD for pneumonia 
Table 4 Adjusted odds ratios, 95\% confidence intervals and $p$ values for the association between patient characteristics, pattern of injury and in-hospital mortality

\begin{tabular}{|c|c|c|c|}
\hline Independent variable & Odds ratio & 95\% Confidence interval & $p$ value \\
\hline \multicolumn{4}{|l|}{ Age (years) } \\
\hline $65-80$ & ref & & \\
\hline $81-90$ & 1.4 & $0.6-3.2$ & 0.44 \\
\hline$\geq 91$ & 3.4 & $1.5-7.6$ & 0.003 \\
\hline History of cardiac disease (Yes) & 2.6 & $1.4-4.7$ & 0.003 \\
\hline History of COPD GOLD 2 or more & 1.3 & $1.4-12.7$ & 0.01 \\
\hline Number of rib fractures & 2.087 & $1.249-3.489$ & 0.005 \\
\hline 1 & Ref & & \\
\hline $2-3$ & 0.9 & $0.4-2.0$ & 0.78 \\
\hline$>3$ & 1.2 & $0.6-2.9$ & 0.56 \\
\hline Multiple unspecified & 2.6 & $1.1-6.0$ & 0.03 \\
\hline \multicolumn{4}{|l|}{ Severity of head injury (AIS) } \\
\hline None or minor & Ref & & \\
\hline Moderate & 0.6 & $0.12-2.4$ & 0.42 \\
\hline Severe or worse & 3.5 & $1.9-6.4$ & $<0.001$ \\
\hline \multicolumn{4}{|l|}{ Severity of abdominal injury (AIS) } \\
\hline None or minor & ref & & \\
\hline Moderate & 2.4 & $0.8-7.4$ & 0.13 \\
\hline Severe or worse & 6.8 & $1.8-25.4$ & 0.004 \\
\hline \multicolumn{4}{|l|}{ Severity of spine injury (AIS) } \\
\hline None or minor & Ref & & \\
\hline Moderate & 1.6 & $0.7-3.9$ & 0.30 \\
\hline Severe or worse & 4.6 & $1.9-11.2$ & 0.001 \\
\hline Need for chest-tube drainage (yes) & 2.0 & $1.1-3.7$ & 0.03 \\
\hline
\end{tabular}

AIS Abbreviated Injury Score, ISS Injury Severity Score

\begin{tabular}{lllr}
\hline Independent variable & Odds ratio & $95 \%$ Confidence interval & $p$ value \\
\hline Gender (male) & 2.4 & $1.4-4.2$ & 0.002 \\
History of COPD (any grade) & 3.9 & $2.2-7.1$ & $<0.001$ \\
Number of rib fractures & & & 0.18 \\
1 & & & 0.03 \\
$2-3$ & 1.8 & $0.8-4.4$ & 0.03 \\
$>3$ & 2.6 & $1.1-6.5$ & $<0.001$ \\
Multiple unspecified & 2.8 & $1.1-7.4$ & 0.28 \\
Severity of head injury (AIS) & 1.356 & $1.163-1.581$ & 0.002 \\
$\quad$ None or minor & & & $0.7-4.3$ \\
$\quad$ Moderate & 1.7 & $1.4-4.3$ & \\
$\quad$ Severe or worse & 2.5 & & 0.14 \\
Severity of abdominal injury (AIS) & & & 0.003 \\
$\quad$ None or minor & & $2.0-26.6$ & 0.02 \\
$\quad$ Moderate & 7.3 & $1.1-3.4$ & \\
Severe or worse & 1.9 & & \\
Need for chest tube drainage (Yes) & & &
\end{tabular}

\footnotetext{
AIS Abbreviated Injury Score
}

Table 5 Adjusted odds ratios, 95\% confidence intervals and $p$ values for the association between patient characteristics, pattern of injury and pneumonia discharged to a nursing facility when compared to non-frail patients [10]. While we did not have these data available, further research on geriatric trauma should definitively focus on these frailty indices. 
The increasing rate of elderly patients admitted with rib fractures as well as the rate of adverse events in the current population results in a considerable use of resources with regard to ICU and hospital admission. Therefore, tailored treatment aimed at fast recovery and discharge to the previous housing facility with a low probability of adverse events a extremely important.

While oral, intravenous or epidural analgesics combined with physical therapy are currently the gold standard for the treatment of rib fractures, specific analgesic therapies may not always be possible (e.g. epidural analgesics and oral anticoagulants) or may even be harmful (morphine induced delirium) in the elderly population [11, 12]. Encouraged by favorable results with regard to ventilator days and risk of complications after surgical rib fixation in patients with flail chest as shown in the randomized trial by Marasco et al., some have advocated surgical rib fixation in the elderly patient with multiple (non flail chest) rib fractures too [13, 14]. A recent retrospective case control study by Fitzgerald et al. supports this strategy; surgical rib fixation was associated with lower rates of pneumonia, respiratory readmissions in ICU and death $[15,16]$.

Despite the promising results, the current study shows that not all patients with multiple rib fractures may be candidates for this approach: spinal injuries-which were present in $8 \%$ of patients-may preclude proper positioning of these patients for surgical rib fixation. Traumatic brain injury (TBI, which was present in $22 \%$ of patients) may require prolonged intubation and mechanical ventilation, and significantly impacts on mortality and may, therefore, decrease the potential benefits of surgical rib fixation with regard to ICU and ventilator times, (ventilator-associated) pneumonia and mortality.

Apart from the risk of selection bias with regard to the number of rib fractures, this study has several other limitations. First, the use of registry data has some important drawbacks, such as the risk of misclassification by AIS, under- or overestimation of the number of rib fractures and the risk of duplicate patients. In addition, apart from data on the use of epidural anesthesia, data on the type and timing of analgesia, and the exact frequency and intensity of physical therapy were not available, which may have a considerable influence on patient outcomes. At last, we did not have data available with regard to some important patient characteristics, such as smoking status, pre-injury cognitive status and housing facility. As stated earlier, these may very well be important determinants of outcome as well.

In conclusion, pneumonia and death occur in about $10 \%$ of elderly patients with rib fractures. Comorbidities and extra-thoracic injuries are common and should be considered when choosing between different treatment options in the elderly patient with rib fractures.
Acknowledgements On behalf of the South West Netherlands Trauma Region Study Group: Onno Boonstra Spijkenisse Medisch Centrum, Spijkenisse; P. Ted den Hoed Ikazia Ziekenhuis, Rotterdam; Tijs Jakma Albert Schweitzer Ziekenhuis, Dordrecht; Jan LM van Niekerk Beatrix Ziekenhuis, Gorinchem; Piet AR de Rijcke Ijsselland Ziekenhuis, Capelle a/d IJssel; Geert R Roukema Maasstad Ziekenhuis, Rotterdam; Vicktor A de Ridder Sint Franciscus Vlietland Gasthuis, Rotterdam; Georg B Schmidt Sint Franciscus Vlietland Gasthuis, Rotterdam; Marco Waleboer Admiraal de Ruyter Ziekenhuis, Goes.

\section{Compliance with ethical standards}

Conflict of interest All authors declare that they have no conflict of interest.

Open Access This article is distributed under the terms of the Creative Commons Attribution 4.0 International License (http://creativeco mmons.org/licenses/by/4.0/), which permits unrestricted use, distribution, and reproduction in any medium, provided you give appropriate credit to the original author(s) and the source, provide a link to the Creative Commons license, and indicate if changes were made.

\section{References}

1. Baidwan NK, Naranje SM. Epidemiology and recent trends of geriatric fractures presenting to the emergency department for United States population from year 2004-2014. Public Health. 2017;142:64-9.

2. Bulger EM, Arneson MA, Mock CN, Jurkovich GJ. Rib fractures in the elderly. J Trauma. 2000;48(6):1040-6. (discussion 6-7).

3. Lotfipour S, Kaku SK, Vaca FE, Patel C, Anderson CL, Ahmed $\mathrm{SS}$, et al. Factors associated with complications in older adults with isolated blunt chest trauma. West J Emerg Med. 2009;10(2):79-84.

4. Battle CE, Hutchings H, Evans PA. Risk factors that predict mortality in patients with blunt chest wall trauma: a systematic review and meta-analysis. Injury. 2012;43(1):8-17.

5. Sampalis JS, Nathanson R, Vaillancourt J, Nikolis A, Liberman M, Angelopoulos J, et al. Assessment of mortality in older trauma patients sustaining injuries from falls or motor vehicle collisions treated in regional level I trauma centers. Ann Surg. 2009;249(3):488-95.

6. Harrington DT, Phillips B, Machan J, Zacharias N, Velmahos GC, Rosenblatt MS, et al. Factors associated with survival following blunt chest trauma in older patients: results from a large regional trauma cooperative. Arch Surg. 2010;145(5):432-7.

7. Shulzhenko NO, Zens TJ, Beems MV, Jung HS, O'Rourke AP, Liepert AE, et al. Number of rib fractures thresholds independently predict worse outcomes in older patients with blunt trauma. Surgery. 2017;161(4):1083-9.

8. Hall DE, Arya S, Schmid KK, Blaser C, Carlson MA, Bailey TL, et al. Development and initial validation of the risk analysis index for measuring frailty in surgical populations. JAMA Surg. 2017;152(2):175 - 82 .

9. Maxwell CA, Mion LC, Mukherjee K, Dietrich MS, Minnick A, May A, et al. Preinjury physical frailty and cognitive impairment among geriatric trauma patients determine postinjury functional recovery and survival. J Trauma Acute Care Surg. 2016;80(2):195-203.

10. Joseph B, Pandit V, Zangbar B, Kulvatunyou N, Hashmi A, Green DJ, et al. Superiority of frailty over age in predicting outcomes 
among geriatric trauma patients: a prospective analysis. JAMA Surg. 2014;149(8):766-72.

11. Kieninger AN, Bair HA, Bendick PJ, Howells GA. Epidural versus intravenous pain control in elderly patients with rib fractures. Am J Surg. 2005;189(3):327-30.

12. McKendy KM, Lee LF, Boulva K, Deckelbaum DL, Mulder DS, Razek TS, et al. Epidural analgesia for traumatic rib fractures is associated with worse outcomes: a matched analysis. J Surg Res. 2017;214:117-23.

13. Leinicke JA, Elmore L, Freeman BD, Colditz GA. Operative management of rib fractures in the setting of flail chest: a systematic review and meta-analysis. Ann Surg. 2013;258(6):914-21.
14. Marasco SF, Davies AR, Cooper J, Varma D, Bennett V, Nevill R, et al. Prospective randomized controlled trial of operative rib fixation in traumatic flail chest. J Am Coll Surg. 2013;216(5):924-32.

15. Fitzgerald MT, Ashley DW, Abukhdeir H, Christie DB. Rib fracture fixation in the 65 years and older population: a paradigm shift in management strategy at a Level I trauma center. J Trauma Acute Care Surg. 2017;82(3):524-7.

16. Zegg M, Kammerlander C, Schmid S, Roth T, KammerlanderKnauer U, Gosch M, et al. Multidisciplinary approach to lifesaving measures in the elderly individuals with flail chest injury with ORIF of Rib fractures: a report of 2 cases. Geriatr Orthop Surg Rehabil. 2012;3(4):164-6. 